\title{
Clinical Profile, Dyslipidemia and ACS - a Correlation
}

\author{
Bikash Dali \\ ' Department of Internal Medicine,TUTH, IOM, Nepal.
}

\section{ABSTRACT}

Introduction: To analyze lipid profile in patients with ACS, and to study the pattern of the involvement and complication in ACS.

Methods: Hundred and eight consecutive cases of ACS, attending the CCU of Tribhuvan University Teaching Hospital fulfilling the criteria, were taken for the present study. Patient from age 30 and older were studied. All cases were scrutinized to detail serial 12 lead EKG, serial cardiac biochemical markers, laboratory test, echocardiographic study. Design of the study was carried out in prospective, cross sectional study.

Results: Hyperlipidemia was present in $61 \%$ of the patients. Only $27 \%$ of them were on statins. Most of them had high cholesterol level 68\%, high Tgl level $75 \%$, Ldl $50 \%$, where as $<40 \mathrm{Hdl}(93 \%$ ) patient were found to be low. $40 \%$ was found to have UAP. In addition patient with hypertension (76\%) diabetes $(65 \%)$ also had comorbidity for obesity $35 \%$, and lipid abnormalities $75 \%$ for triglycerides, $66 \%$ for TC, $50 \%$ for LDL-C, $93 \%$ for low HDL-C, and a family history of CAD in $57 \%$.

Conclusions: The outcome of this study showed that the majority are male, relatively younger as compared to Western population. USA and STEMI were the dominant types of ACS. Strong correlations between TC, LDL-C, and low HDL-C in patient with ACS were noted. Majority of patients had hypertension, IHD in their families and Hyperlipidemia diabetes, smoking as the major risk factors. Better control of risk factors and the awareness of preventive strategies are needed.

Keywords: ACS; clinical profile; lipid profile.

\section{INTRODUCTION}

Atherosclerosis is a chronic, multifocal immuno inflammatory; fibroproliferative disease of mediumsized and large arteries mainly driven by lipid accumulation. ${ }^{1}$ The fundamental etiologic mechanism shared by all the forms of ACS is an imbalance between myocardial oxygen supply and demand. The most common cause of ACS is thrombus formation over a preexisting atherosclerotic plaque that has undergone disruption or erosion. Plaques vulnerable to disruption and thrombosis formation commonly have a large lipid core with elevated tissue factor content, a thin fibrous cap, and enhanced inflammatory activity within the plaque. When endothelial erosion of a plaque occurs, the subendothelial connective tissue is exposed, allowing platelets to adhere and eventual thrombus to form at the plaque surface. ${ }^{2}$ Alternatively, during plaque disruption, the fibrous cap tears or fissures to expose the highly thrombogenic lipid core to arterial blood,

Correspondence: Dr. Bikash Dali, Department of Internal Medicine,TUTH, IOM, Nepal. Email: bsdali208@gmail.com, Phone:+977-9851035935. 
leading to platelet aggregation and thrombus formation. The final common pathway leading to thrombus formation is platelet aggregation, which is mediated by the GP Ilb/IIla receptors. In UA and NSTEMI, the intraarterial thrombus does not fully occlude the lumen, and some ante grade blood flow remains intact. However, clumps of activated platelets at the surface of an intra-luminal thrombus as well as components of the disrupted plaque may be swept downstream into the distal myocardial vascular bed. These micro emboli may cause microscopic foci of myocardial necrosis and are believed to be primarily responsible for the release of biomarkers of myocardial infarction seen in patients with NSTEMI. ${ }^{3}$ The contrasting scenario is for the thrombus to fully occlude the arterial lumen, resulting in an acute Q-wave myocardial infarction (commonly with ST elevation). UA/NSTEMI primarily caused by a nonocclusive thrombus benefit from a treatment regimen including anti-thrombotic and antiplatelet agents..$^{3,4}$

\section{The objectives of the study}

To study of the clinical profile, measure the outcomes of cardiac biochemical markers, lipid profile in patient and correlate clinically with acute coronary syndrome.

\section{METHODS}

These was a prospective cross sectional study of acute coronary syndrome; clinically and correlate them with lipid profile findings in Nepalese patients. This study was carried out in Tribhuvan University Teaching Hospital (TUTH), in-patient Department of CCU from 2009 to 2012 . This hospital is a tertiary care hospital and referral center with all the facilities. During the study period all the cases of ACS patient attending the inpatient department were consecutively enrolled in the study. A total of 108 patients seen in the CCU with a primary diagnosis of ACS were studied according to the guidelines for ACS; fulfilling inclusion criteria and a set of baseline investigation needed for the study of acute coronary syndrome were done on the patient.

\section{Inclusion criteria}

1. Presenting or admitted to hospital with symptoms suspected to represent UA or NSTEMI. 2. New onset or worsening symptoms within six hours of presentation to the ER. 3. Patient Age group from 30 Years and older 4. At least two of the three following additional criteria: Age greater than or equal to 30 years. Troponin $\mathrm{T}$ or $\mathrm{I}$ or CK-MB above the upper limit of normal for the local Institution ECG changes compatible with ischemia. 5. Written informed consent dated and signed 6. Both sexes male and female. Recent ( $\leq 7$ days) ACS

Exclusion criteria. Age $<30$ years, Hemorrhagic stroke within the last 12 months, Associated Renal disease Severe renal insufficiency (i.e., estimated creatinine clearance $<20 \mathrm{ml} / \mathrm{min}$ ), Left Ventricular Failure, NYHA IV, Persistent severe hypertension, defined as systolic blood pressure of $\geq 180 \mathrm{~mm} \mathrm{Hg}$ or diastolic pressure of $110 \mathrm{~mm} \mathrm{Hg}$, active bleeding or at high risk for bleeding (e.g., cirrhosis of the liver, any history of intracranial hemorrhage), Scheduled/planned cardiac catheterization, $\mathrm{PCl}, \mathrm{CABG}$ or other invasive procedure planned in the 24 weeks, Co-morbid condition with life expectancy less than six months, Any contraindication to UFH or LMWH, Refused informed consent .

Statistical Analysis. Performed using the software SPSS for Windows, Version 11.5. Categorical variables were compared by chi square test and the continuous variables are presented as mean (+/- SD) and were compared by unpaired t-test. Odd's ratios were calculated and presented wherever necessary. A probability value of $<0.05$ was considered statistically significant.

\section{RESULTS}

A total no of 108 patients were enrolled in this prospective, cross sectional study in the CCU, of Tribuhvan University Teaching Hospital. Among them gender wise $51 \%$ patient were male.

\begin{tabular}{|c|c|c|}
\hline $\begin{array}{l}\text { Socio-Demographic } \\
\text { information }\end{array}$ & $\begin{array}{l}\text { Number } \\
(\mathrm{N}=108)\end{array}$ & $\begin{array}{l}\text { Percentage } \\
\text { (\%) }\end{array}$ \\
\hline \multicolumn{3}{|l|}{ Marital Status } \\
\hline Single & 4 & 3.7 \\
\hline Married & 94 & 87.0 \\
\hline Widowed & 10 & 9.3 \\
\hline \multicolumn{3}{|l|}{ Address } \\
\hline Urban & 63 & 58.3 \\
\hline Rural & 45 & 41.7 \\
\hline \multicolumn{3}{|l|}{ AGE } \\
\hline$<30$ & 1 & .9 \\
\hline $30-40$ & 24 & 22.2 \\
\hline $40-50$ & 13 & 12.0 \\
\hline $60-70$ & 23 & 21.3 \\
\hline $70-80$ & 14 & 13.0 \\
\hline$>80$ & 3 & 2.8 \\
\hline \multicolumn{3}{|l|}{ GENDER } \\
\hline MALE & 55 & 50.9 \\
\hline FEMALE & 53 & 49.1 \\
\hline \multicolumn{3}{|l|}{ EDUCATION } \\
\hline ILLITERATE & 34 & 31.5 \\
\hline READ WRITE ONLY & 27 & 25.0 \\
\hline HIGH SCHOOL & 15 & 13.9 \\
\hline
\end{tabular}


Dali Lipid profile in patients with coronary Artery disease

\begin{tabular}{|c|c|c|}
\hline BACHELOR & 22 & 20.4 \\
\hline POST GRADUATE & 10 & 9.3 \\
\hline \multicolumn{3}{|l|}{ DIABETES } \\
\hline NO & 38 & 35.2 \\
\hline YES & 70 & 64.8 \\
\hline \multicolumn{3}{|l|}{ HYPERTENSION } \\
\hline NO & 26 & 24.1 \\
\hline YES & 82 & 75.9 \\
\hline \multicolumn{3}{|c|}{ HYPERCHOLESTEROLEMIA } \\
\hline NO & 43 & 39.8 \\
\hline YES & 65 & 60.2 \\
\hline \multicolumn{3}{|l|}{ SMOKING } \\
\hline NO & 24 & 22.2 \\
\hline YES & 84 & 77.8 \\
\hline \multicolumn{3}{|l|}{ PREVIOUS MI } \\
\hline NO & 104 & 96.3 \\
\hline YES & 4 & 3.7 \\
\hline \multicolumn{3}{|l|}{ ALCOHOLIC } \\
\hline NEVER & 57 & 52.8 \\
\hline CURRENT & 51 & 47.2 \\
\hline \multicolumn{3}{|l|}{ PVD } \\
\hline NO & 78 & 72.2 \\
\hline YES & 30 & 27.8 \\
\hline \multicolumn{3}{|l|}{ Family history } \\
\hline No & 47 & 43.5 \\
\hline Yes & 61 & 56.5 \\
\hline \multicolumn{3}{|l|}{ WHR } \\
\hline Normal & 34 & 31.5 \\
\hline Abnormal & 74 & 68.5 \\
\hline \multicolumn{3}{|l|}{ BMI } \\
\hline Normal & 43 & 39.8 \\
\hline Over weight & 27 & 25.0 \\
\hline \multicolumn{3}{|l|}{ STATIN } \\
\hline NO & 78 & 72.2 \\
\hline YES & 30 & 27.8 \\
\hline
\end{tabular}

Age ranged from 30 to $>80$ years. Number of patient studied in this group were as follow: $23 \%$ belonged to young patient $<45$ years with ACS, next were age from 40 to 50 years (12\%), 50 to 60 years (28\%), 60 to 70 years $21 \%, 70$ to 80 years $13 \%$ and $>80$ years $2.9 \%$.Socio-demographical information is given in table 1 respectively.

The incidence of types ACS according to clinical profile is shown in table 4 . On analyzing the clinical profile of the patient most common $(94,87 \%)$ patient were married, followed by widowed $(10,9.3 \%)$, and single $(4,3.7 \%)$. Most of the studied populations were illiterate $31 \%$ followed by read write only $25 \%$, high school $13.9 \%$, bachelor $20.4 \%$ and post graduate 9.3\%.student. Bulks of the patient were from the urban areas $59 \%$, and the rest from rural areas $41 \%$.

\begin{tabular}{|c|c|c|}
\hline \multicolumn{3}{|c|}{ Table 2. Laboratory Findings. } \\
\hline $\begin{array}{c}\text { Total } \\
\text { Cholesterol }\end{array}$ & Number $(n=108)$ & Percent (\%) \\
\hline Normal & 35 & 32.4 \\
\hline High & 73 & 67.6 \\
\hline \multicolumn{3}{|l|}{ Triglycerides } \\
\hline Normal & 27 & 25.0 \\
\hline High & 81 & 75.0 \\
\hline \multicolumn{3}{|l|}{ HDL } \\
\hline$>=40$ & 8 & 7.4 \\
\hline$<40$ & 100 & 92.6 \\
\hline \multicolumn{3}{|l|}{ LDL } \\
\hline Normal & 54 & 50.0 \\
\hline High & 54 & 50.0 \\
\hline
\end{tabular}

\begin{tabular}{|c|c|c|c|}
\hline \multirow{3}{*}{ Profile } & \multicolumn{2}{|c|}{ CK_MB } & \\
\hline & \multirow[b]{2}{*}{ Normal(\%) } & \multicolumn{2}{|c|}{ P Value $<0.05$} \\
\hline & & $\operatorname{High}(\%)$ & \\
\hline \multicolumn{4}{|c|}{ Hypercholesterolemia } \\
\hline No & $22(51.2 \%)$ & $21(48.8 \%)$ & .008 \\
\hline Yes & $17(26.2 \%)$ & $48(73.8 \%)$ & \\
\hline \multicolumn{4}{|l|}{ LDL } \\
\hline Normal & $27(50.0 \%)$ & $27(50.0 \%)$ & .003 \\
\hline High & $12(22.2 \%)$ & $42(77.8 \%)$ & \\
\hline
\end{tabular}

Of the 108 patient studied 70 patient (65\%) were found to have diabetes; $82(76 \%)$ hypertension, hypercholesterolemia 65(60\%), smoking 84(78\%), alcoholic $51(47 \%)$, PVD $30(27.8 \%)$. Only $28 \%$ of the studied populations were on statins. Elevated TGL in $75 \%$, low HDL in $93 \%$, and high LDL in $50 \%$ of the patient studied were documented. Patient with clinical profile having elevated level of Hypercholesterolemia was also correlated with ck_mb and was found to be $74 \%(n=48)$, statistically significantly strong correlation $\mathrm{p}<0.008$, compared to subjects with normal TC level $48 \%(n=21)$. Similar significantly strong correlation was also seen with LDL, $p<0.003$. 


\begin{tabular}{|c|c|c|c|}
\hline \multirow[b]{2}{*}{ Profile } & \multicolumn{2}{|c|}{ Troponin } & \multirow[b]{2}{*}{$\begin{array}{l}\text { P Value } \\
<0.05\end{array}$} \\
\hline & Normal (\%) & High (\%) & \\
\hline \multicolumn{4}{|l|}{ Gender } \\
\hline Male & $28(50.9 \%)$ & $27(49.1 \%)$ & .028 \\
\hline Female & $16(30.2 \%)$ & $37(69.8 \%)$ & \\
\hline \multicolumn{4}{|c|}{ Hyperchole sterolemia } \\
\hline No & $25(58.1 \%)$ & $18(41.9 \%)$ & .003 \\
\hline Yes & $19(29.2 \%)$ & $46(70.8 \%)$ & \\
\hline \multicolumn{4}{|l|}{ Chest pain } \\
\hline No & $14(63.6 \%)$ & $8(36.4 \%)$ & .014 \\
\hline Yes & $30(34.9 \%)$ & $56(65.1 \%)$ & \\
\hline \multicolumn{4}{|l|}{ Heart rate } \\
\hline Normal & $31(51.7 \%)$ & $29(48.3 \%)$ & .010 \\
\hline Tachycardia & $13(27.1 \%)$ & $35(72.9 \%)$ & \\
\hline \multicolumn{4}{|l|}{ BP } \\
\hline $\begin{array}{l}\text { Not } \\
\text { Hypertensive }\end{array}$ & $18(62.1 \%)$ & $11(37.9 \%)$ & .006 \\
\hline Hypertensive & $26(32.9 \%)$ & $53(67.1 \%)$ & \\
\hline \multicolumn{4}{|l|}{ BMI } \\
\hline No & $12(27.9 \%)$ & $31(72.1 \%)$ & .027 \\
\hline Yes & $32(49.2 \%)$ & $33(50.8 \%)$ & \\
\hline \multicolumn{4}{|l|}{ WHR } \\
\hline Normal & $18(52.9 \%)$ & $16(47.1 \%)$ & .080 \\
\hline Abnormal & $26(35.1 \%)$ & $48(64.9 \%)$ & \\
\hline
\end{tabular}

Similar significantly strong correlation was also seen with LDL, $p<0.003$. Significant correlation were also seen in patient with hypercholesterolemia, $p<.003$, gender wise, $p<.028$, chest pain wise, $p<.014$, heart rate wise, $p<.010$, hypertensivs, $p<.006$, and BMI wise $p<.027$ than the normal subjects. Though clinically was noted to be significant in correlating WHR presented with abnormal ratio that had high level of troponin positive than with those with normal WHR, we found it not to be statistically significant in the current study, suggesting a possibility of low sample size.

Significant clinically and statistically correlation was found between high level subjects with total cholesterol $\mathrm{p}<.000$, high TGL level $\mathrm{p}<.007$, and high LDL level subjects $p<.006$, than those with normal levels but with positive troponin finding. A correlation with low HDL level though clinically relevant could not be established, the reason could be of low sample size or other factors influencing the study subjects.

We attempted to find out the correlation significance of clinical profile of the patient with types of acs in the number of subjects under our study group with the history of acs admitted in our hospital. The results are shown in table 3-7. We found very interesting outcomes of our research. We found a negative inverse correlaton of clinical profiles, though relavant with types of ACS in the low HDL group $p<.303$ showed no correlation with these variables though they were clinically significant relevant. A positive statistically significant correlation did show up in the subjects with hypercholesterolemia $p<.037$, than the normal subjects with types of ACS. $40 \%$ with hypercholesterolimia had STEMI, followed by $31 \%$ NSTEMI, and $29 \%$ unsable angina compared to those with normal finding. Statistical significant correlation were noted with total cholesterol $p<.001$, high TGL $p<.008$, and high LDL $p<.019$ with types of ACS in compared to the subjects with normal parameters, where STEMI was found to be $44 \%$ followed by UAP $29 \%$ and NSTEMI $27 \%$ respectively.

Table 5. Correlation between Troponin and Lipid profile $(n=108)$.

\begin{tabular}{|c|c|c|c|}
\hline \multirow[t]{2}{*}{ Profile } & \multicolumn{2}{|c|}{ Troponin } & \multirow{2}{*}{$\begin{array}{r}\text { P Value } \\
<0.05\end{array}$} \\
\hline & Normal (\%) & High (\%) & \\
\hline \multicolumn{4}{|c|}{ Total cholesterol } \\
\hline Normal & $23(65.7 \%)$ & $12(34.3 \%)$ & .000 \\
\hline High & $21(28.8 \%)$ & $52(71.2 \%)$ & \\
\hline \multicolumn{4}{|c|}{ Triglycerides } \\
\hline Normal & $17(63.0 \%)$ & $10(37.0 \%)$ & .007 \\
\hline High & $27(33.3 \%)$ & $54(66.7 \%)$ & \\
\hline \multicolumn{4}{|l|}{ LDL } \\
\hline Normal & $29(53.7 \%)$ & $25(46.3 \%)$ & .006 \\
\hline High & $15(27.8 \%)$ & $39(72.2 \%)$ & \\
\hline
\end{tabular}

Table 6. Correlation of clinical profile with types of ACS ( $n=108)$.

\begin{tabular}{|c|c|c|c|c|}
\hline \multirow{2}{*}{ Profile } & \multicolumn{3}{|c|}{ Types of ACS } & \multirow{2}{*}{$\begin{array}{c}\mathrm{P} \\
\text { Value } \\
<0.05\end{array}$} \\
\hline & STEMI (\%) & NSTEMI (\%) & UAP (\%) & \\
\hline \multicolumn{5}{|c|}{ Hypercholesterolemia } \\
\hline No & $10(23.3 \%)$ & $10(23.3 \%)$ & $23(53.5 \%)$ & .037 \\
\hline Yes & $26(40.0 \%)$ & $20(30.8 \%)$ & $19(29.2 \%)$ & \\
\hline \multicolumn{5}{|l|}{ HDL } \\
\hline$>=40$ & $1(12.5 \%)$ & $2(25.0 \%)$ & $5(62.5 \%)$ & .303 \\
\hline$<40$ & $35(35.0 \%)$ & $28(28.0 \%)$ & $37(37.0 \%)$ & \\
\hline
\end{tabular}




\begin{tabular}{|c|c|c|c|c|}
\hline \multicolumn{5}{|c|}{$\begin{array}{l}\text { Table 7. Correlation between Types of ACS and Lipid } \\
\text { profile }(n=108) \text {. }\end{array}$} \\
\hline \multirow[b]{2}{*}{ Profile } & \multicolumn{3}{|c|}{ Types of ACS } & \multirow{2}{*}{$\begin{array}{c}P \\
\text { Value } \\
<0.05\end{array}$} \\
\hline & STEMI (\%) & $\begin{array}{l}\text { NSTEMI } \\
(\%)\end{array}$ & UAP (\%) & \\
\hline \multicolumn{5}{|l|}{$\begin{array}{l}\text { Trigly } \\
\text { cerides }\end{array}$} \\
\hline Normal & $7(25.9 \%)$ & $3(11.1 \%)$ & $17(63.0 \%)$ & .008 \\
\hline High & $29(35.8 \%)$ & $27(33.3 \%)$ & $25(30.9 \%)$ & \\
\hline \multicolumn{5}{|l|}{ LDL } \\
\hline Normal & $13(24.1 \%)$ & $13(24.1 \%)$ & $28(51.9 \%)$ & .019 \\
\hline High & $23(42.6 \%)$ & $17(31.5 \%)$ & $14(25.9 \%)$ & \\
\hline \multicolumn{5}{|c|}{$\begin{array}{l}\text { Total } \\
\text { cholesterol }\end{array}$} \\
\hline Normal & $4(11.4 \%)$ & $10(28.6 \%)$ & $21(60.0 \%)$ & .001 \\
\hline High & $32(43.8 \%)$ & $20(27.4 \%)$ & $21(28.8 \%)$ & \\
\hline
\end{tabular}

\section{DISCUSSION}

The prevalence of acute coronary syndromes is increasing. The major pathophysiologic mechanism is plaque rupture or fissuring with superimposed thrombus. Today, ACS is one of the commonest causes of hospitalization. ${ }^{1}$ Each year, more than 1.4 million patients in the United States ${ }^{2}$ and more than four million worldwide $^{3}$ are hospitalized with ACS. These numbers will continue to rise as the prevalence of patients with dyslipideamia, obesity and diabetes increases. ${ }^{3}$

The syndromes of unstable angina, nonST-elevation MI (NSTEMI) and ST-elevation MI (STEMI) are a continuum, and the pathophysiology is heterogeneous and dynamic. Clinical presentation depends on the severity of the arterial injury; the size and type of thrombus formed the extent and duration of ischemia, and the amount of previous myocardial necrosis.

Between $2 \%$ and $15 \%$ of patients diagnosed with unstable angina subsequently develop Q-wave MI. The unstable angina classification developed by Braunwald 6 is based on the severity of symptoms, their clinical context, and the intensity of medical treatment. The classification has been validated clinically, ${ }^{7}$ has been shown to correlate with coronary angiographic findings , 8 and has now been updated to include troponin levels. ${ }^{9}$

The main findings of our study were the strong association of acute coronary syndrome with high TC, TGL, low HDL and high HDL level in both subjects. This study shows a high prevalence of multiple cardiovascular risk factors (smoking, hypertension, lipid abnormalities and diabetes) among adolescents in Nepalese population.

The prevalence of multiple risk factors increases at age- group 30-40 years with an exponential increase in age group 50-60 years. The demographic data shows that the patient population in this study is similar to other high-risk coronary heart disease populations shown in other studies. Study subjects in present study were having a mean age of $51.07 \pm 11.39$ years, which is comparable to studies by OASIS registry. In comparison to our study the average age in other studies such as BLITZ (67.0 \pm 12.5$)$, ENACT (64.5), PRAIS-UK $(66.0 \pm 12.0)$ and Euro heart survey (EHS) $(64.6 \pm 12.5)$ were higher. In present study, around $84 \%$ of ACS patients were under the age of 60 years. As per the OASIS registry, the proportion of Indian patients younger than 65 years of age was $77 \%$ as compared to $51 \%$ in developed countries. Most prevalent age range in our study was $50-70$ years which is comparable to the study carried out in Scotland by Capewell et al. Present study showed predominance of male $(51 \%)$ with early onset of ACS as compared to females (49\%), which shows the similarity with Jose et al study. Women appear to be less susceptible to CHD than men although they seem to lose this protection after the menopause, presumably because of hormonal changes.

Among study population, 39\% patients were diagnosed to have UA followed by STEMI in 33\% patients and $29 \%$ NSTEMI. This is in agreement with the previous study, where in EHS (42.3\%) and GRACE registry $(30 \%)$ was STEMI patients. Whole treatment pattern is comparable to GRACE study. In the present study, antiplatelet, anticoagulant and lipid lowering agent were found to be used in minimum patients, but maximum during their hospital stay, except few patients in which those drug class was contraindicated. Use of antiplatelet was less in present study compared to other studies such as EHS, Kramer et al, BLITZ, GRACE, PRAIS-UK, ENACT, CREATE registry and OASIS, registry. ${ }^{7-10}$

Dyslipideamia, obesity have been shown to have important consequences for coronary heart disease morbidity and mortality ${ }^{20}$ and are strongly associated with numerous coronary heart disease risk factors, such as elevated levels of total cholesterol, low-density lipoprotein cholesterol, triglycerides, blood pressure, C-reactive protein, and insulin resistance, as well as with lower levels of high-density lipoprotein cholesterol, an important protective factor for coronary heart disease. ${ }^{20}$

Dyslipideamia and obesity pose a serious public health concern in Nepal in view of the rapid changes in lifestyle with processed foods increasingly replacing traditional foods. In a previous study of subjects with chest pain it was reported that Troponin was positive in 160 subjects (31.9\%) and negative in 323 (64.3\%) subjects. ${ }^{14}$ They also reported higher incidence of Acute Myocardial Infarction, Acute heart failure, and death due to cardiac event in the subjects with chest pain 
and positive Troponin confirming that it is a powerful, independent and valuable tool for risk stratification in patients with acute chest pain. Our data indicated that, of the subjects with chest pain (108), 56 subjects $(65 \%)$ were detected positive and a proportion of subjects $30(35 \%)$ were detected negative for Troponin. Accordingly; those $65 \%$ subjects with chest pain are at high risk of developing cardiac event. It is well known that increased levels of low density lipoproteins (LDL), Triglycerides (TG) and total cholesterol (TC) and decreased levels of high density lipoproteins (HDL) are also indicative of increased incidence of cardiac events and are considered a risk factor. ${ }^{15-17}$ Therefore in this study the relationship between levels of lipid profile parameters and the results of Troponin test in predicting cardiac events was evaluated. The mean TC level of the subjects with positive Troponin (46, 71\%) was well above the recommended desirable level $(<200 \mathrm{mg} /$ dl), ${ }^{18}$ thus indicating those subjects are susceptible to develop cardiac event. The level of total cholesterol of the subjects with negative Troponin test but with chest pain $(19,29 \%)$ was significantly lower than that of the subjects with positive Troponin above confirming the importance of maintaining total cholesterol levels below the recommended level. ${ }^{18-19}$ Similarly the mean TG level of the subjects with positive Troponin (54,67\%) was well above the both the recommended desirable level, $18(<150 \mathrm{mg} / \mathrm{dl})$ and the level of TG of the subjects with negative Troponin test but with chest pain $(27,33 \%)$. Further subjects with only chest pain the TG level was slightly lower than the recommended safe level. Increased level of LDL is highly atherogenic as it could get oxidized and initiates the atheroma formation. Thus it is believed that increased level of LDL than the recommended level is a high risk factor in the development of cardiac event. The mean LDL level of the subjects with positive Troponin $(39,72 \%)$ was well above the recommended desirable level $1<130$ $\mathrm{mg} / \mathrm{dl}) .{ }^{18-19}$ Further the mean LDL level of the subjects with negative Troponin test but with chest pain (15, $28 \%$ ) was well below the recommended level and confirmed the importance of maintaining lower levels of LDL in preventing future cardiac event. Thus our data indicated that the subjects who developed chest pain due to cardiac event as confirmed by positive Troponin test had significantly greater levels of TC.TG, LDL when compared to those levels in subjects without cardiac event as indicated by negative Troponin test. On the other hand lower HDL level ( $<40 \mathrm{mg} / \mathrm{dl}$ ) is also regarded as a cardiac risk factor, ${ }^{19-21}$ and the mean HDL level of the subjects with positive Troponin (100, 93\%) was lower than the recommended safe level. This also indicates that the development of cardiac event was associated with reduced levels of $\mathrm{HDL}$ than the recommended level. The total cholesterol level, TG, and LDL levels of the subjects with positive Troponin was significantly ( $p$
$<0.000, \mathrm{p}<0.007, \mathrm{p}<0.006)$ greater than subjects with negative troponin, and significant difference was observed for TC between healthy subjects and subjects with a negative Troponin test but with chest pain. Likewise significant differences were observed for TG and LDL between these groups. Similar significant correlation was observed with ck_mb and TC, $p<.008$, LDL $p<.003$, and types of ACS. Subjects with high TC value, STEMI 32(44\%), followed by UA 21(29\%) and NSTEMI 20(27\%) showed strong association and probability than those of normal subjects. These data indicated that the chest pain due to cardiac event as determined by positive Troponin test, ck_mb is closely associated with elevated levels of TC, LDL, and TG and also with significantly reduced HDL. The present study also shows that development of obesity and central obesity is associated with simultaneous increase in many biological risk factors such as changes in blood pressure levels and glucose and lipid abnormalities. Significant statistical correlation were observed in clinical profiles of the patient, marital status, age wise, gender wise and BMI with troponin and found to be significant $p<.008, p<.000, p<.028$ respectively than the normal subjects. Similar findings have been reported from the Bogalusa Heart Study, NHANES, and CARDIA study and many other North American and European studies. The present study shows that the increase in risk factors in Nepalese population starting at about the age of 30 years and beyond, focus of prevention should be at subjects lower than this age..$^{20-22}$

\section{CONCLUSIONS}

High rates of dyslipideamia were noted in middleaged and elderly patients. Diabetes Mellitus and hypertension are important risk factors for young ACS patient age group, especially in association with hypercholesterolemia. Developing and implementing effective population-based intervention strategies focusing on diabetes are warranted to lower the CHD risk for patient with. Better control of risk factors and the awareness of preventive strategies are needed to be implemented promptly and swiftly.

This research shows that patients who developed chest pain due to cardiac event as confirmed by positive Troponin test had lipid parameters in the risk levels as suggested by ATP III. Therefore the subjects who had lipid profile levels within risk level were at a greater risk of developing chest pain due to cardiac event. Therefore it is advisable to screen and identify those subjects with risk levels of lipid profile parameters and advise them to control their lipid profiles to maintain within the levels as per recommended. Cigarette smoking and hypercholesterolemia are the two most important, independent modifiable major risk factors for ACS at 
younger age. In conclusion, greater heterogeneity in the adopting of a "modern" lifestyle may lead to larger within population differences in risk factor distributions that may serve to strengthen the relationship of the conventional risk factors with coronary heart disease, as seen for the anthropometric variables. Preventive strategies and accelerated efforts to create awareness are needed and point to the urgent need for targeted public health interventions.

\section{REFERENCES}

1. C.J.L. Murray, A.D. Lopez . The global burden of disease: a comprehensive assessment of mortality and disability from disease, injuries and risk factors in 1990 and projected to 2020. Harvard School of Health, Boston (Mass) (1996)

2. The World Health Report 1999: The double burden: Emerging epidemics and persistent problems. WHO 1999. Available at: <http://www.who.org

3. World Health Statistics 2008: WHO. Available at: <http:// www.who.int/whosis/whostat/EN_WHS08_TOCintro. pdf $>$.

4. M.M. Ibrahim, L.J. Appel, H.H. Rizk, S. Helmy, J. Mosley, Z. Ashour, et al.Cardiovascular risk factors in normotensive and hypertensive Egyptians J Hypertens, 19 (2001), pp. 1933-1940

5. R. Beaglehole International trends in coronary heart disease mortality and incidence rates J Cardiovasc Risk, 6 (1999), pp. 63-68

6. K. Okrainec, D.K. Banerjee, M.J. Einsenberg Coronary artery disease in the developing world Am Heart J, 148 (2004), pp. 7-15

7. S. Yusuf, S. Hawken, S. Ounpuu, T. Dans, A. Avezum, F. Lanas, et al. INTERHEART study investigators. Effects of potentially modifiable risk factors associated with myocardial infarction in 52 countries (The INTERHEART Study): case-control study. Lancet, 364 (2004), pp. 937-942

8. C.L. Johnson, B.M. Rifkind, C.T. Sempos, M.D. Carroll, P.S. Bachorik, R.R. Briefel, et al. Declining serum total cholesterol levels among US adults. The National Health and Nutrition Examination SurveysJAMA., 269 (23) (1993), pp. 3002-3008

9. S. Mendis, D. Abegunde, S. Yusuf, S. Ebrahim, G. Shaper, H. Ghannem WHO-PREMISE (phase I) study Group). WHO study on prevention of recurrences of myocardial infarction and stroke (WHO-PREMISE Bull World Health Organ, 83 (2005), pp. 820-828

10. B. Lamarche, J.-S. Despre, S. Moorjani, B. Cantin, G. Dagenais, P. Lupien, et al. Prevalence of dyslipidemic phenotypes in ischemic heart disease (prospective results from the Quebec cardiovascular study) Am J Cardiol, 75 (1995), pp. 1189-1195

11. J.J. Genest, J.R. McNamara, J.M. Ordovas, J.L. Jenner, S.R. Silberman, K.M. Anderson, et al. Lipoprotein cholesterol, apolipoprotein A-I and B and lipoprotein(a) abnormalities in men with premature coronary artery disease. J Am Coll Cardiol, 19 (1992), pp. 792-802
12. A.J. Hammoudeh, M. Izraiq, E. Al-Mousa, H. Al-Tarawneh, A. Elharassis, Z. Mahadeen, et al. Serum lipid profiles with and without CAD: Jordan hyperlipidemia and related targets study (JoHARTS-1) East Mediterr Health J, 14 (2008), pp. 24-32

13. H. Rubins, S. Robins, D. Collins, A. Iranmanesh, T. Wilt, D. Mann, et al.Distribution of lipids in 8,500 men with coronary artery disease.Am J Cardiol, 75 (1995), pp. 1196-1201

14. V. Mohan, R. Deepa, S.S. Rani, G. Premolatha,Prevalence of coronary artery disease and its relationship to lipids in a selected population in South India: the Chennai Urban Population Study (CUPS No.S).J Am Coll Cardiol, 38 (2001), pp. 682-687

15. G. Assmann, H. Schulte, von. Eckardstein, Y. Huang $\mathrm{Y}$, High density lipoprotein cholesterol as a predictor of coronary heart disease risk. The PROCAM experience and pathophysiological implications for reverse cholesterol transport.Atheroclerosis, 124 (Suppl) (1996), pp. S11-20

16. C.A. Aguilar-Salinas, G. Olaiz, V. Valles, J.M. Torres, FJ. Gómez Pérez, JA. Rull, et al.High prevalence of low HDL cholesterol concentrations and mixed hyperlipidemia in a Mexican nationwide survey. J lipid Res, 42 (8) (2001), pp. 1298-1307

17. H. Al-Kateb, W. Marzzour, M. Shameah, M. Juoma. Coronary risk factors of angiographically assessed patients from Syria.J Cardiovasc Risk, 5 (1998), pp. 31-35

18. S. Ericsson, M. Eriksson, S. Vitols, K. Einarsson, L. Berglund, B. Angelin. Influence of age on the metabolism of plasma low density lipoproteins in healthy males. J Clin Invest, 87 (2) (1991), pp. 591-596

19. Z. Chodorowski, J.S. Anand, J. Foerster, M. Gruchała, K. Chlebus. Differences in lipid profile in patients with first myocardial infarction occurring at different ages.Borgis New Medicine, 2 (2004), pp. 48-51

20. R.A. Kronmal, K.C. Cain, Z. Ye, G.S. Omenn.Total serum cholesterol levels and mortality risk as a function of age. A report based on the Framingham data Arch Intern Med, 153 (1993), pp. 1065-1073

21. E. Ferrannini. Metabolic abnormalities in hypertension: a lesson on complexity. Hypertension, 18 (1991), pp. 636-639

22. D.B. Allison, K.R. Fontaine, J.E. Manson, J. Stevens, T.B. Van Itallie. Annual death attributable to obesity in the United States. JAMA, 828 (1999), pp. 1530-1538 